\author{
Abstracts of Papers read at the Scientific Meeting of the International \\ Medical Society of Paraplegia held on 27 and 28 July 1962 at Stoke Mande- \\ ville Hospital, Aylesbury, England.
}

\title{
STUDIES ON SEGMENTAL INNERVATION
}

\author{
By Dr. A. Grossiond and Dr. M. MAURY (France) \\ The Raymond Poincaré Hospital, Garches, and The Rehabilitation Centre, Fontainebleau
}

MANY things remain unknown regarding the motor segments: precise anatomoclinical studies are rare, and the presentation of tables demonstrating the segmental innervation of skeletal muscles show astonishing differences.

Putting aside preconceived ideas and theories we have considered this problem in the light of daily semeiological study of motor function in paraplegia and tetraplegia and we have endeavoured, by comparative study of a certain number of muscle tests, to make as precise as possible the relative topography of the upper level of different motor nuclei in the spinal cord.

The studies concern the analysis of the muscle charts obtained from stabilised spinal cord lesions of different levels in traumatic or other lesions. Charts were used according to the usual techniques with figures from $\circ$ to 5 and then compared to the corresponding sensory charts. To get the best results from these charts it was necessary to consider only lesions where the upper level was clinically precise. These studies were carried out simultaneously at: The Raymond Poincaré Hospital, Garches, and The Rehabilitation Centre, Fontainebleau.

Lower Limb. Forty-eight limbs have been studied (Dr. A. Grossiord and Dr. Buzacoux) and the same charts used as at Fontainebleau. From this study it appears that the sartorius seems to be the first to appear, followed very quickly by the iliopsoas, the pectineus and the rectus femoris; the adductors follow, as well as the lower portions of the quadriceps and the gracilis which is of special interest in paraplegics as it also appears in lesions at $\mathrm{L}_{3}$ and more so at $\mathrm{L}_{4}$. Further down follow a series of muscles, the most outstanding being the tibialis anticus; but the upper level of the nuclei of the gluteus minimus and medius, tensor fasciae latae and the medial hamstrings seem to be very close to that of the tibialis anticus; we have the impression that in this group it is the gluteus minimus which has the highest position-by only a very small margin - and that the inner hamstrings are the lowest. Less than one segment below appear the gluteus maximus, the extensor digitorum, then the tibialis posticus and medius followed by the peronei. Even lower, appear the biceps femoris, the gastrocnemius and lastly and distinctively below the flexor digitorum and the small muscles of the foot.

Upper Limb. Thirty-two limbs have been studied (Dr. Maury and Dr. G. Barthes).

They have studied the segmental innervation of the principal muscles of the upper limb, the innervation of which are layered between $\mathrm{C}_{5}$ to $\mathrm{T}_{\mathrm{I}}$ inclusive. At the level of $\mathrm{C}_{5}$ appear almost simultaneously the deltoid, biceps, rotators of the shoulders (the external rotators are placed higher than the internal rotators). Then at the level of C6 follow the pectoralis major, the pronators; the triceps 
possibly overlaps a little on C6 but certainly corresponds to $\mathrm{C}_{7}$. This is also the segment where the palmar muscles and the latissimus dorsi originate, furthermore the extensor digitorum, the extensor and flexor carpi ulnaris and the extensor carpi radialis. At the level of $\mathrm{C} 8$ appear the flexors of the fingers, the interossei, lumbricals and the opposing muscles of the thumb which in fact belong essentially to TI and are, without any doubt, the lowest situated in the upper limb. The comparison of neighbouring muscles, two by two, is precise in respect of the upper level of their nuclei of origin. Therefore, for instance, the triceps is always below the brachio-radialis, and the pectoralis major is lower than the pronators, nearly at the same level as the palmaris and slightly above the latissimus dorsi.

The authors do not claim that this study is beyond certain criticisms, such as:

The relatively few cases which have been studied.

The fact that they have applied the same reasoning and the same deductions to muscles which have their nuclei spread over three or four segments, as to those which are nearly uni-segmental.

This is a preliminary study which will be completed in due course. However, at least, it has been possible to establish the segmental innervation of muscles on a clinical basis which will constitute a new working approach. The details of this study will be published in this journal at a later date with diagrams and literature.

\title{
SEGMENTAL INNERVATION OF THE LIMBS
}

\author{
By Dr. Jean Benassy (France)
}

OVER 400 cases of tetraplegia and paraplegia have been analysed by the author in the past ten years and some important facts seem to have emerged from the study, the following are some of these facts:

In multi-segmental innervation the upper root appears to be the predominant root. As far as the upper limbs are concerned, C5 nerve root, apart from having the functions of abduction of the arm, external rotation of the shoulder and flexion of the forearm, must be considered in addition to $\mathrm{C}_{4}$, as having an inspiratory function. The C6 segment which includes the teres major, latissimus dorsi, pectoralis major, sub-scapularis, extensor carpi radialis and pronator teres, is mostly an expiratory segment. The remainder of the innervation of the upper limb appears to follow the classical pattern except that one must note that the triceps seems to have its innervation in the C6 segment. It is noteworthy that the small muscles of the hand belong to the Ti territory.

As far as the lower limbs are concerned, the sartorius seems to be the highest innervated muscle ( $\mathrm{LI}$ ) and if one considers its function, this appears to be the starting muscle in sprinting races. It is also noteworthy that in the lower limbs the upper adductors are of high innervation and that the $\mathrm{L}_{2}$ and $\mathrm{L}_{3}$ segments seem to command the forward push of the lower limb. The innervation of the tibialis anticus and tibialis posticus (both $\mathrm{L}_{4}$ ) have as their most important function, inversion of the foot. The $\mathrm{L}_{4}$ and $\mathrm{L}_{5}$ roots act as the stabilising roots of the lower limb. The SI root is responsible for the back thrust of the leg, the forward action of the leg being performed mainly by $\mathrm{L}_{2}$ and $\mathrm{L}_{3}$. 


\title{
Discussion
}

Guttmann, L. (England) stressed the significance of the triceps as one of the most important muscles particularly for the quadriplegic. Although this muscle was a multisegmentally innervated one $(\mathrm{C} 6, \mathrm{C}, \mathrm{C} 8)$, there were variations in the degree of innervation in the three segments. It was certainly not true, as suggested by previous authors (Foerster) that in complete lesions below C6 the triceps remained permanently paralysed in every case. The segment of $\mathrm{C} 6$ might compensate for the loss of $\mathrm{C}_{7}$ and $\mathrm{C} 8$. The degree of functional recovery of the triceps due to the remaining innervation of C6 largely depended on the early management of the upper limbs in quadriplegics. If the triceps were overstretched by keeping the forearm flexed, the functional recovery, if at all, would be very poor. This had to be considered from the beginning by both the medical and nursing staff, as well as by the physiotherapist. Another interesting muscle from the point of view of segmental supply was the abductor pollicis brevis, which the speakers had not mentioned. This muscle was almost entirely unisegmentally innervated by $T_{I}$ (Foerster), in contrast to the opponens and interossei which had their main supply in C8. Another almost entirely unisegmentally innervated muscle was the tibialis anterior: its supply was $\mathrm{L}_{4}$, in contrast to that of the tibialis posterior, which received a large innervation from $\mathrm{L}_{5}$.

Benassy, $\mathcal{F}$. (France) entirely agreed that the long head of the biceps had a special innervation from C6, and he entirely endorsed Guttmann's view on the early management of quadriplegics.

Weiss, M. (Poland) found that, for crutch-walking, apart from the trapezius, the great pectoral and the extensor carpi radialis, the triceps was the most important muscle.

\section{AMYLOIDOSIS IN CHRONIC PARAPLEGIA}

\author{
By C. R. Tribe, M.A., B.M., B.Ch., D.T.M. and H. \\ Stoke Mandeville Hospital (England)
}

A SHORT review of literature on amyloidosis in paraplegia showed that all previous authors had incriminated pressure sores with underlying osteomyelitis as the chief aetiological factor.

Out of I 22 post-mortems on chronic paraplegia, 48 had histologically proven amyloidosis. In all cases this was secondary in type. The average survival time of these cases was 10.8 years after paraplegia.

In 46 of these cases the amyloidosis was due to chronic infection resulting as a direct consequence of paraplegia.

The gross pathological features were reviewed. It was concluded that the diagnosis of amyloidosis at post-mortem was unreliable and should never be made without histological proof.

A method for grading the severity of the amyloidosis in each case was proposed based on histological grading of the amyloid in individual organs.

The microscopic distribution of amyloid in different tissues was shown and illustrated by lantern slides. The most important finding was an apparent predilection for amyloid deposition in the kidneys with relative sparing of the other major viscera. The prognostic significance of this finding, which requires further proof, was discussed.

Other microscopic findings included no evidence of severe cardiac amyloidosis, remarkable sparing of lung and central nervous tissue, severe desposition 
in the pituitary gland when looked for and involvement of the gastro-intestinal tract in all of the 22 cases in which this tissue was available.

In 27 out of the 46 cases associated with parapelgia the amyloidosis was considered to be the major cause of death. In a further I4 cases the amyloidosis had contributed to death. In all cases amyloidosis had killed by renal involvement.

Finally the aetiology of amyloidosis in paraplegia was considered. It was concluded that in most cases a combination of chronic pressure sores, often with underlying osteomyelitis, and chronic urinary tract infection were the underlying causes. However this series did reveal that in some cases renal suppuration by itself could lead to amyloidosis.

It is hoped that full details of this study will be published at a later date.

\title{
Discussion
}

Pollard, A. C. (England) was particularly interested in the case in which the liver was grossly infiltrated with amyloid, and he asked Dr. Tribe whether there had been jaundice and how generalised was the amyloid in the liver.

Tribe, $C . R$. (England): The amyloid was completely generalised and the patient's liver was even worse than shown in the slide, and yet there was no jaundice.

Guttmann, L. (England) wanted to know details about amyloidosis in the central nervous system -in particular, the brain, including the pituitary gland and also the spinal cord. As far as he knew, there was little known about amyloidosis in the central nervous system. In any case, there seemed to be an amazing difference between amyloidosis in the various internal organs of the body.

Tribe, C. R. (England): In the brain the vessels of the choroid plexus were involved but not the vessels in the tissues of the brain or the spinal cord. In the pituitary, only the posterior part was affected by amyloid.

Grossiord, $A$. (France) discussed the difficulties of clinical diagnosis of amyloidosis and asked Dr. Tribe's view about the value of rectal biopsy and examination of the skin, especially the sweat glands. He suggested that when bedsores were excised the skin surrounding the bedsores should be examined.

Tribe, C. R. (England) had carried out rectal biopsies on people suffering from chronic rheumatoid arthritis, but without much success. He was, however, convinced that if it were possible to obtain amyloid anywhere it was to be found in the gastrointestinal tract. Amyloid could also be found in the gums in small amounts.

\section{ANTERIOR CERVICAL DECOMPRESSION AND FUSION FOR CERVICAL MYELOPATHY}

\author{
By Phillip Harris, F.R.C.S.E., F.R.C.P.E. \\ Royal Infirmary, Edinburgh, Scotland
}

CERviCal myelopathy is a common disease, and cervical spondylosis is probably the commonest cause of spinal cord compression. It is generally agreed that operative treatment should not be delayed for cervical myelopathy, but old age, very severe spinal cord damage and a long history may be considered to be contraindications to surgery.

Various surgical procedures have been advocated, such as a limited, or more often an extensive decompressive laminectomy, with or without opening the dura, and with or without division of dentate ligaments. 
Many surgeons still advocate laminectomy, but very few now in addition attempt to remove the hard osteophytes which are compressing the anterior aspect of the spinal cord, because retraction of the cord in these patients is fraught with danger.

The results of the operations mentioned above are not in fact very satisfactory, as has been shown by careful follow-up examinations, and by radiographic studies, including in several patients, repeat myelography. Indeed, a number of these patients have shown definite clinical deterioration following laminectomy and some have required an extension of the laminectomy. Four patients in the series discussed in this paper, who had had an anterior cervical decompression and fusion procedure, had already had an extensive laminectomy a year or more before; and an additional patient who had deteriorated clinically after laminectomy was found to have a severe degree of subluxation of the cervical spine, and this patient had an anterior fusion procedure after the subluxation was corrected.

The most rational form of treatment for cervical myelopathy would appear to be removal of the osteophytes by an anterior approach to the cervical spine, followed by bony fusion of the associated vertebral bodies.

The operation (Smith \& Robinson, I958; Cloward, I958) has been modified, and certain of the instruments which were invented by Wiltberger (1953) for pre-fit dowel intervertebral body fusion for patients with lumbar disc protrusion, and which were utilised by Cloward for cervical disc lesions, have been further modified, and new instruments have in addition been devised. Thus the guard sleeve for the drill has been made so that it will slip into and remain locked in the disc; also this sleeve has had a handle attached to it to prevent it from moving during drilling; and a special director has been made to guide the guard sleeve to the centre of the disc which is to be drilled; the use of a depth gauge, and a check X-ray taken during the operation allows the surgeon to estimate the depth which must be drilled before the posterior common ligament is reached.

The opening made through the disc and adjacent vertebral bodies, and the osteophytes, is half an inch in diameter, and a high speed grinder with a small spherical burr driven off compressed nitrogen and turning at 70,000 revolutions per minute, is used in the hole to clear away the remaining osteophytes situated anterior to the spinal cord and the associated nerve roots.

With the patient lying supine, and with $25 \mathrm{lb}$. head traction, an incision is made in a skin crease in the right carotid triangle. It is possible to expose the anterior aspect of the spinal column from $\mathrm{C}_{2}$ to DI vertebral body, by this approach.

The patient is retained in bed in the supine position for Io days and is then allowed up and about wearing a simple felt-leather collar, which is discarded after 2 to 3 weeks. Careful clinical follow-up is carried out and in addition check straight $\mathrm{X}$-rays of the neck and myelograms, and in some patients cine-radiograms are being done.

Twenty-one patients have been treated, in II, one disc (and osteophytes) has been excised, in 9, two discs, and in I patient, three. If three or more discs are involved in the disease, laminectomy (usually of four or five laminae), with opening of the dura, has been the operation of choice.

The early results are very promising and are definitely better than those obtained after laminectomy. The follow-up so far is short, the longest being I6 months. There have been no complications. In further communications details will be given regarding selection for operation, details of technique, long- 
term results of 'posterior' operations, and the results, both clinical and radiological, of the anterior decompression and fusion procedure.

A similar type of operation may be used for certain injuries of the cervical spine and for certain neoplasms and infectious conditions. (A cine film was shown of the operative technique; and the film also contained cine-radiographic studies in cervical myelopathy.)

The modified and new instruments were made by Mr. R. C. Gibb, Edinburgh.

\section{Discussion}

Osborne, G. (England) asked whether the benefit was derived from the anterior decompression or from the fusion. It was certainly possible to fuse the cervical spine in a more simple and less hazardous way by simple bone graft of two vertebrae. This had been done satisfactorily for some years. What benefit was derived from the anterior cervical decompression?

Harris, P. (Scotland): This operation was not hazardous and he had seen no trouble so far from this procedure. His experience was that fusion alone was not sufficient for severely paraparetic patients.

$M e a d, S$. (U.S.A.) said he had no quarrel with Harris's procedure when confined to patients with severe paraparesis. However, he did not think this should be done for people without paraparesis but suffered only from pain. One case in the U.S.A. developed a Brown-Séquard syndrome post-operatively.

Walsh, F. F. (England) asked how soon Harris allowed free movement of the neck after operation.

Harris, $P$. (Scotland): The patient remained strictly in bed with supporting packs for Io days. Then, the supports were removed in stages and he was allowed to sit up. Within two weeks he was up and about with a collar for approximately two to three weeks, then the collar was taken off. Control X-rays were taken.

Michaelis, L. S. (England): Mr. Harris had said at one point that this operation was 'simple'. It was important to emphasise that this operation brilliantly done at one particular centre might be repeated elsewhere with disastrous effects. It should not be done indiscriminately.

Hardy, A. G. (England) heartily supported this. He said this applied also to another method-plating of the broken spine-of which Dr. Guttmann did not approve, but he still felt that this was indicated in the right circumstances.

Hancock, D. O. (England) had noticed in the last photograph of the fused spine a little subluxation in the intervertebral space below the level of the fusion and wondered if the leverage were not increased because of the subluxation in a weak cervical spine.

Guttmann, L. (England) found Mr. Harris's anterior approach very interesting and probably better than the old approach of a conventional laminectomy or hemi-laminectomy. He referred to paraplegics admitted after these latter operations to Stoke Mandeville who had walked into hospitals elsewhere with pain either without or with only slight disturbance of walking and developed after the usual posterior approach a paraplegia, which was, of course, a great disaster. The anterior approach was perhaps the more physiological one. With regard to Hancock's remark about subluxation below the fusion, it was not infrequent in traumatic paraplegics that the vertebrae above and below the consolidated fractured vertebrae became hyper-mobile, and a similar principle obviously also applied to the fused vertebrae. Therefore, it was a physiological reaction to the fusion and not a pathological subluxation.

\section{REFERENCES}

Cloward, R. B. (1958). F. Neurosurg. 15, 602.

SMith, G., \& Robinson, R. A. (1958). f. Bone ft Surg. 40-A, 607.

Wiltberger, B. R. (1953). Amer. F. Surg. 86, 723. 


\title{
STONE DISEASE IN PARAPLEGIA
}

\author{
By M. Damanski, M.D. \\ The Liverpool Regional Paraplegic Centre, \\ Promenade Hospital, Southport (England)
}

THE author reports on observations on stone disease at the Liverpool Regional Parapelgic Centre, Southport, over a period of 15 years. He mentions the basic theories of the aetiology of stone formation under the headings

(I) Nucleus: (a) intra-renal; (b) extra-renal.

(2) Growth of stone.

(3) Impaired elimination.

He then goes on to comment on some of the basic principles involved.

Mentioning the special features of stone formation in paraplegia he lists, concentration of urine, stasis, infection and fourthly a specific factor, metabolic or non-metabolic of neurogenic origin, but states that this has not yet been conclusively proved. At his Centre, successful prophylaxis of stone has resulted from (I) early mobilisation, (2) use of urinary acidifiers and a high protein diet, (3) high fluid intake, and (4) efficient catheter drainage at first, followed by elimination of residual urine and catheter at a later stage.

He describes the incidence of stone at the Southport Centre from January I947 to I96I and the statistics show a low incidence after the initial years. Dealing with the mortality he stated 12 out of the 20 patients affected with stone were dead from uraemia. He concludes by saying that though stone formation in paraplegia has fallen to a negligible figure, he considered the long-term prognosis of a patient who has developed stone in the kidney in paraplegia, is a poor one.

\section{DisCUSSION}

Pelot, G. (France) agreed that the incidence of both bladder and renal stones had greatly decreased in paraplegics since suprapubic cystostomy had been abandoned.

Benassy, $\mathcal{F}$. (France) drew attention to the resemblance between stone formation in the kidney and para-articular calcification of joints following cerebral damage and felt there was a relationship between stone disease and para-articular calcification.

Walsh, F. F. (England) agreed from the Stoke Mandeville experience that there had been a profound decline in stone formation since suprapubic cystostomy had been abandoned. It occurred much less with the indwelling Foley catheter, provided that the catheter was changed at least twice or three times a week, although it occurred in those patients in which the urethral catheter was changed only once a week or once a fortnight.

Guttmann, L. (England): With regard to early drainage mentioned by Damanski, using an indwelling catheter, he definitely disagreed with this principle. In his experience over many years, intermittent catheterisation by the doctor or surgeon in charge using a non-touch technique was the most satisfactory management of the paralysed bladder in the early stages. He agreed that this method was not so convenient for the surgeon or doctor but was definitly the safest for the patient. This had been proved again and again at Stoke Mandeville with the many paraplegics admitted immediately or within the first few days after injury. Only in those hospitals where there were no proper facilities for the ideal management of the paralysed bladder did he agree that Gibbons' 
catheter was probably the safest method of drainage by indwelling catheter, although even this catheter did not prevent accumulation of mucus and sediment or infection.

Sutcliffe Kerr, $A$ (England) was of the opinion that, from all that Damanski had shown, recumbency was probably the most important single factor. Those patients treated by early mobilisation remained free from any complication. Early sitting position was a very important factor in the prevention of stone formation.

Block, $\mathcal{F}$. (Northern Ireland) suggested that other factors must also play a part in stone formation. In the Spinal Unit for coloured people in South Africa, the great majority of spinal injuries were due to stab wounds (over 50 per cent.). These patients were mobilised within the first week of injury, as the stability of the spine was not interfered with, and yet these patients developed stone formation.

\title{
METABOLIC CHANGES IN PARAPLEGIA
}

\author{
b. Jfessor P. E. GREgolre \\ Laboratoire de Biologie Clinique, Hôpital Universitaire St. Pierre, Brussels \\ and Dr. P. Houssa and Dr. A. TRICoT \\ Centre de Traumatologie et de Réadaptation, Hôpital Universitaire \\ Brugmann, Brussels (Belgium)
}

SINCE citrate forms a complex with calcium, thus reducing the concentration of ionised calcium, the authors have made a study to determine concentration of citric acid in the serum of 15 normal men and 7 normal women, in comparison with 17 paraplegic men and 2 paraplegic women. The determination of citric acid was carried out by Ardle's method, which is based on the conversion of citric acid into pentabromo-acetone and the spectrophotometric determination of the colour complex which the latter forms with sodium sulphate.

Results. The average concentration of serum citric acid in normal men did not differ from that in normal women. Serum citric acid concentration during fasting states showed no significant difference between normal subjects and paraplegics. Tests carried out on the same person during a period of several weeks showed a remarkable consistency in serum citric acid concentration. There was, however, a considerable difference between citric acid concentration in the urine between normal subjects and paraplegics, which was found greatly reduced in the latter. The influence of bacterial infection of the urinary system is considered to be the important factor in reducing concentration of urinary citrate.

The investigations did not allow conclusion that there is an increased concentration of citric acid in paraplegic patients, and no relationship was found between concentration of citric acid and pathological ossifications in paraplegics.

\section{Discussion}

Silver, $\mathcal{F}$. (England) said that most were familiar with investigations showing no abnormalities in calcium metabolism, and the papers of Dr. Tricot and his colleagues had confirmed this also with regard to citric acid. He also drew attention to the fact that paraplegics in later stages could run a slow pulse of $40 / 50$ per minute and prolonged periods of low blood pressure ( 80 or $90 / 50 \mathrm{~mm}$. Hg.). One would expect in these patients 
to find disturbances of water and sodium metabolism, yet these patients handled water and sodium loads quite normally in experimental studies.

$\operatorname{Hardy,} A$. G. (England) referred to extensive investigations by American authors who had tried to make these tests sensitive enough to show abnormalities which were not revealed with standard methods.

\title{
UROLOGICAL AND NEUROLOGICAL OBSERVATIONS FOLLOWING ANAESTHETIC PROCEDURES ON PATIENTS WITH SPINAL CORD INJURIES
}

\author{
By A. Rossier, M.D. \\ Zurich, Switzerland
}

THIS communication is a summary of studies on the effect of topical anaesthesia on bladder activity carried out in co-operation with Dr. E. Bors at the Spinal Cord Injury Service of the Veterans Administration Hospital, Long Beach, California. The studies were concerned with the reflex activity which exists between the urethral mucosa and the detrusor and pelvic floor musculature and its possible effect on bladder dysfunction. In particular, the role of afferent impulses arising from the urethral and vesical mucosa, in relation to changes of capacity and residual urine, as well as reflex activity of the muscles of the pelvic floor, were investigated.

Altogether, 52 patients-3I tetraplegics and 2 I paraplegics-were examined. Urethral anaesthesia was achieved by instillation of $5 \mathrm{cc}$. of 2 per cent. Xylocaine daily in 22 patients, vesical anaesthesia by the injection of $90 \mathrm{cc}$. of 0.25 Pontocaine solution in 37 patients, and combined anaesthesia was used in 22 patients.

Improvement of bladder activity was most frequent following urethral anaesthesia, less with combined anaesthesia and least with vesical anaesthesia. Temporary balance of bladder function was equally frequent with individual urethral and vesical anaesthesia: permanent balance of bladder function was equally frequent following urethral and combined anaesthesia. The number of patients who achieved permanent balance of bladder function was smaller than those with temporary bladder balance.

The anal reflex was least frequently diminished following any of these procedures. Most frequently diminished was the response of the bulbo-cavernosus reflex. Vesical anaesthesia was more effective in that respect than urethral anaesthesia.

Neither bladder nor pelvic floor responses could be correlated to the level and extent of the spinal cord lesion.

From all these findings, it is concluded that impulses originating from the urethral mucosa receptors have a similar effect on the reflex arcs of the sacral segments as previously described on the vesical mucosa receptors. The authors feel that topical anaesthesia of urethral and vesical mucosa is a precautionary measure in the prevention of autonomic dysreflexia from urological instrumentation.

A full description of these studies is given in volume 87 of the fournal of Urology. 


\title{
Discussion
}

Pool, G. M. (Holland) had confirmed Rossier's experience in the blocking of peripheral nerve fibres of the urinary system and referred to a new drug which had been brought out by the Ciba Foundation.

Guttmann, L. (England) was particularly interested in the effect of anaesthesia of the mucosa in decreasing spasticity: a clear proof of how infection irritates the peripheral nerve ramifications and acts as a strong afferent stimulus to the isolated cord.

\section{ELECTRONIC CONTROLS FOR THE PARALYSED (POSSUM)}

\author{
By R. MALING \\ National Spinal Injuries Centre, Stoke Mandeville Hospital (England)
}

TODAY the substantially totally paralysed are given a life expectancy approaching the normal span. Since their personalities remain normal or even enhanced, the situation provides a challenge and responsibility to devise forms of control over their immediate environment with effective means of communication and to endeavour to provide them with a skill to earn their livelihood.

Limb prostheses are extremely useful for the functions of daily living but are inefficient in providing means for earning a livelihood. The work described here may be called 'By-Pass Controls' as they deliberately by-pass the site of the disability and take their control from any residual movement.

This work was started by a small technical group of the League of Friends of Stoke Mandeville Hospital. The Director of the National Spinal Injuries Centre, Dr. Guttmann, kindly provided accommodation within his Research Department and the Polio Research Fund has provided a grant to finance a threeyear project.

A control site should preferably have normal innervation, unaffected muscular function, high acceleration, be capable of sustained use and have aesthetic acceptability.

The patient who inspired this work had as his only form of control, a police whistle suspended above his lips. The mouth can produce good sustained pressure or suction independent of breathing and from an engineering point of view has remarkable pneumatic control, producing in the average mouth a pressure of $60 \mathrm{~mm}$. Hg. and a suction of $100 \mathrm{~mm}$. Hg.

A pneumatic switch makes an electrical contact which starts a rotary switch and the continuation of light, sustained suction will cause the arm to pass over a bank of some ten contacts, the position being shown on an indicator panel. When the suction is released at the required position, a power relay will switch whatever electrical circuit is connected to it-first time on, second time off. The Possum multi-purpose control provides on/off control for such things as bell, light, radio, page turner, heater, electric blanket, telephone, television, respirator change, etc.

A loudspeaker telephone is used and the control obtains a line, waits for the dialling tone and then dials ' $\mathrm{O}$ ' or ' 100 ', the operator's voice comes out of the loudspeaker and the person asks for the number through a small microphone fixed near to the mouth. The selection procedure is the same for incoming calls. Local numbers are prefixed 'Special Assistance' when required. 
The Possum Typewriter Grid I, uses both 'Suck' and 'Puff' for its operation, thereby squaring the functions controllable. The speed for this Grid is approximately 26 w.p.m. Other grid systems have been devised which will permit speeds of over 100 w.p.m.

Control over a typewriter keyboard may be generalised to control over any suitable keyboard. Many machine tools nowadays are based on co-ordinate tables.

The terms of reference of the project are to extend the Possum controls to all forms of severe disablement and congenital deformity and to all forms of suitable electro-mechanical, electronic, pneumatic and hydraulic equipment.

The Ministry of Health has agreed to a trial of some 20 prototypes in various hospitals, institutions and private homes throughout the country. These will be paid for by the Polio Research Fund.

Present developments include: more detailed control on any function; adaptation to provide a wider range of functions; a system for writing and drawing; an investigation into the control sites available from the various types of disablement; teaching methods for controls; and patient controlled teaching machines for education purposes.

\title{
Discussion
}

Agerholm, M. (England) mentioned a case of high lesion of polio with respiratory disturbance, who had brought with her a similar design with which she could manage all the things described by the speaker. The model had been designed by the patient's husband. They used an intercom around the house and the patient used the device I8 hours a day, which made life for her and her family much easier. The main difference between the two devices was that her patient controlled the device by biting. With regard to control of the typewriter, the patient's husband proposed to use a code which was more commonly known than that described by Maling.

Maling, $R$. (England) said they had endeavoured to submit the most efficient coding system possible to enable the most severely disabled patient to lead a useful life indefinitely. By biting, the patient had only one control, but with blowing and sucking and varying the pressure of these several levels of pressure were available. For most quadriplegics four levels were usually sufficient. The code used in Possum was between three and four times as efficient as the Morse code mentioned by Agerholm.

Guttmann, L. (England) said that Maling's apparatus had tremendous possibilities and represented a completely new approach in the management of quadriplegics and other high lesions, who could not use their arms. It made the lives of these unfortunate people really worth while living and diminished the burden for their families.

\section{STUDIES ON ENERGY EXPENDITURE OF CONDITIONING EXERCISES IN THE REHABILITATION OF PARAPLEGICS}

\author{
Dr. M. WeISS \\ Poland
}

THE investigations were carried out by the author and his co-workers at the University Rehabilitation Unit, Konstancin near Warsaw, on 2I male and female paraplegics of an age varying from I4 to 52 years. The patients were examined 
in recumbent or standing position, during walking exercises and in the swimming. pool.

Ambulation exercises produced an increase in the amount of pulmonary ventilation by 6 to 20 litres per minute, as compared with resting values of 4 to 9 litres, and there was also a rise of oxygen consumption by 225 to $684 \mathrm{ml}$. per minute, as compared with resting values of 189 to $356 \mathrm{ml}$. per minute. During walking exercises, a 4 to 20 times higher energy expenditure was found in paraplegics as compared with normal subjects.

The effect of treatment on the energy expenditure is shown in a case of incomplete lesion at C6 with partial paralysis of upper and lower limbs, who was examined three times during five months of treatment. Five weeks after injury, the patient was able to cover about I 7 metres in three minutes, consuming 128.29 $\mathrm{ml}$. oxygen per metre. After ambulation exercises of four months, she was able to walk 34 metres, requiring only $65.7 \mathrm{ml}$. oxygen per metre.

Finally, it is pointed out that there is a lower oxygen consumption and smaller energy expenditure if the exercises are carried out in a swimming-pool.

\section{ANNOUNCEMENTS}

On the 7 th and 8th June 1963, the Royal College of Surgeons, Edinburgh, is organizing a two-day International Symposium on Spinal Cord Injuries. Further information may be obtained from the Secretary, Royal College of Surgeons, Edinburgh. It is planned to combine this Scientific Meeting with the National Stoke Mandeville Games, which will be held for the first time in Edinburgh. Further details can be obtained from Mr. Phillip Harris, F.R.C.S., Royal Infirmary, Edinburgh.

The I963 Annual General Meeting followed by the Scientific Meeting of the International Medical Society will take place at Stoke Mandeville Hospital, Aylesbury, on the 26th and 27th July. The main subjects for discussion will be (a) Ureteric Reflux and (b) Spina Bifida.

The I963 International Stoke Mandeville Games will take place in Aylesbury from the 24 th to $27^{\text {th }}$ July.

In 1964, the International Stoke Mandeville Games will be held in Tokyo, immediately after the Olympic Games.

\section{FIRST BRITISH COMMONWEALTH PARAPLEGIC GAMES IN PERTH, AUSTRALIA}

These Games were held from the Ioth to I 7 th November I962, and Ioo paraplegic sportsmen and sportswomen from Australia, England, India, New Zealand, Northern Ireland, Scotland, Singapore, and Wales took part. The Games were an unqualified success, and the paraplegics stood up very well to the long journeys by 'plane. The Games were organized by a special committee, led by Dr. George Bedbrook, the Surgeon in charge of the Paraplegic Unit in Perth, and Mr. Hugh Leslie, M.P.

It is hoped that the Second Paraplegic Commonwealth Games will take place in 1966 in Jamaica. 